\title{
miR-378a-5p improved the prognosis and suppressed the progression of hepatocellular carcinoma by targeting the VEGF pathway
}

\author{
Haibo Zou ${ }^{1}$, Lan Yang ${ }^{2}$ \\ ${ }^{1}$ Department of Hepatobiliary Surgery, ${ }^{2}$ Department of Oncology Centre, Sichuan Academy of Medical Sciences and Sichuan Provincial People's \\ Hospital, Chengdu 610072, China \\ Contributions: (I) Conception and design: All authors; (II) Administrative support: L Yang; (III) Provision of study materials or patients: H Zou; (IV) \\ Collection and assembly of data: All authors; (V) Data analysis and interpretation: H Zou; (VI) Manuscript writing: All authors; (VII) Final approval \\ of manuscript: All authors. \\ Correspondence to: Lan Yang, PhD. Department of Oncology Centre, Sichuan Academy of Medical Sciences and Sichuan Provincial People's Hospital, \\ No. 32, West Section 2, First Ring Road of Chengdu, Chengdu 610072, China. Email: lanyang0729@163.com.
}

Background: The malignant tumor hepatocellular carcinoma (HCC) has a poor prognosis and ineffective
therapeutic options. miR-378a-5p is a micro-ribonucleic acid (miRNA) that is overexpressed in many
cancers. However, its role in the progression of human HCC is unclear.
Methods: Quantitative real-time polymerase chain reaction (qRT-PCR) was used to measure miR-378a-5p
levels in tissues from patients with HCC and from HCC cell lines. Following transfection, flow cytometry
and cell viability assays were used to measure cell proliferation. HCC cell invasive and migration capacities
were assessed using Transwell assays. Western blots were performed with HCC cells to identify the
expression of vascular endothelial growth factor (VEGF).
Results: The HCC tissues and cells had significantly reduced miR-378a-5p expression compared with
normal liver tissues and cells, while miR-378a-5p mimics suppressed the colony formation, viability,
migration and invasive capacity of HCC cells. The HCC tissues and cell lines had upregulated VEGF
expression. In HCC cells, miR-378a-5p expression was negatively correlated with VEGF expression, and
miR-378a-5p targeted VEGF in HCC cells.

Conclusions: miR-378a-5p improved the HCC prognosis and suppressed HCC progression by targeting the VEGF pathway.

Keywords: Hepatocellular carcinoma (HCC); miR-378a-5p; vascular endothelial growth factor; migration; invasion; progression

Submitted Nov 02, 2019. Accepted for publication Dec 26, 2019.

doi: $10.21037 /$ tcr.2020.01.46

View this article at: http://dx.doi.org/10.21037/tcr.2020.01.46

\section{Introduction}

Among malignant tumors, hepatocellular carcinoma (HCC) is the sixth most common in terms of occurrence and cancer-related death $(1,2)$. Typically, HCC treatment involves surgery-based comprehensive therapies. However, the HCC prognosis remains poor, even following surgical resection, as there is a high frequency of recurrence and cancer cell migration into adjunct normal tissues $(3,4)$. The
5 -year postoperative recurrence rate of $\mathrm{HCC}$ is $>60 \%$, mainly due to recurrence and chemoresistance $(5,6)$. Therefore, novel molecular mechanisms must be developed to treat tumor growth and migration.

Micro-ribonucleic acids (miRNAs) are 19-22 nucleotides long and noncoding, and induce mRNA degradation by binding of the target mRNA 3'-untranslated region (UTR) or inhibiting translation (7). Studies have found 
that miRNAs have key functions in many physiological and pathological processes, and miRNAs act as oncogenes or tumor-suppressive genes to regulate cancer progression (8). Accumulating evidence shows that in liver cancer, miRNAs have possible applications as tissue-specific biomarkers. Fang et al. found that miR-188-5p directly targeted fibroblast growth factor 5 (FGF5) to suppress HCC tumor cell proliferation and metastasis (9). In human HCC, miR-1180 promotes resistance to apoptosis via nuclear factor (NF) $-\kappa B$ signaling pathway activation (10). Other miRNAs, including miR-345, miR-487a, and miR-613, are abnormally expressed and promote or suppress HCC incidence and development (11-13). Therefore, the unique expression features of miRNA may form a basis for novel markers for diagnostic and therapeutic targets in HCC.

miR-378a-5p is obtained from miR-378, which has oncogenic properties and is expressed in many cancers $(14,15)$. Kooistra et al. found that miR-378a-5p negatively regulates oncogene-induced senescence (16). miR-378a$5 \mathrm{p}$ has been reported to suppress proliferation in some tumor cells, including renal cell carcinoma (17), triplenegative breast cancer (18), and colorectal cancer (15). Guo et al. found that high miR-378 levels decreased vascular endothelial growth factor (VEGF) production, which correlates with the most aggressive and poorly differentiated form of gastric cancer (19). Interestingly, studies found that the VEGF pathway is more highly expressed in HCC, which may promote HCC migration, invasion, and angiogenesis $(20,21)$. Nevertheless, miR-378a-5p's effects in regulating HCC biology by targeting the VEGF pathway remain unclear.

Here, we hypothesized that miR-378a-5p suppresses HCC progression by targeting VEGF, and we investigated the potential molecular mechanism of miR-378a-5p and its correlation with the VEGF pathway in HCC progression. We investigated miR-378a-5p expression in HCC cell lines and tissues from human patients, analyzed miR-378a-5p cellular functions, namely invasion, cell viability, colony formation, and migration, in HCC cells, and examined the fundamental mechanisms of miR-378a-5p functions in liver cancer.

\section{Methods}

\section{Patients and samples}

Fifty primary liver cancer samples and their adjacent normal tissue samples from liver cancer patients who underwent surgical treatment at the Sichuan Academy of Medical
Sciences and Sichuan Provincial People's Hospital (Sichuan, China) between 2015 and 2017 were used in this study. The patients' clinicopathological parameters, including sex, age, serum alpha-fetoprotein (AFP), lymph node metastasis, tumor size, tumor-node-metastasis (TNM) stage, vascular invasion, and distant metastasis, were recorded. The Sichuan Academy of Medical Sciences and Sichuan Provincial People's Hospital Ethics Committee approved all study protocols.

\section{Cell cultures and transfection}

We purchased human HCC Hep3B and SNU-449 cells from American Type Culture Collection (Manassas, VA, USA). We authenticated the Hep3B and SNU-449 cells with short tandem repeat profiling. High-resolution screening and interspecies cross-contamination detection were performed using the AmpFLSTR ${ }^{\mathrm{TM}}$ Identifiler $^{\mathrm{TM}}$ Plus PCR Amplification Kit. Dulbecco's modified Eagle's medium (DMEM; Invitrogen, Carlsbad, CA, USA) was used to culture the HCC cells. The culture medium was incubated at $37{ }^{\circ} \mathrm{C}$ in $5 \% \mathrm{CO}_{2}$ and humidified air and was supplemented with $10 \%$ fetal bovine serum and $1 \%$ streptomycin/penicillin (Gibco). The HCC cells were transfected with miR-378a-5p mimics and negative control (NC) mimics (ZoonBio Biotechnology Co., Ltd., Nanjing, Jiangsu, China) using Lipofectamine ${ }^{\mathrm{TM}} 2000$ (Invitrogen, Carlsbad, CA, USA).

\section{Western blot analysis}

We prepared human HCC tissue samples and cell lysates in a buffer mixture containing $1 \mathrm{~mL}$ radioimmunoprecipitation assay (Beyotime, Shanghai, China). Sodium dodecyl sulfatepolyacrylamide gel was used to separate the total protein, which was shifted to polyvinylidene difluoride membranes (EMD Millipore, Billerica, MA, USA) at $320 \mathrm{~mA}$ at $4{ }^{\circ} \mathrm{C}$ for $2 \mathrm{~h}$. Non-fat milk (10\%) was used to block the membranes, which were next incubated with the primary antibodies (anti-VEGF-A: 1:1,000 dilutions, Abcam, Eugene, OR, USA) overnight. Horseradish peroxidase-conjugated secondary antibody [Peroxidase-AffiniPure Goat AntiRabbit IgG $(\mathrm{H}+\mathrm{L})$, 1:200 dilution, ZSGB-Bio, Nanjing, Jiangsu, China] was used to probe the membranes at room temperature for $2 \mathrm{~h}$. The protein bands were visualized with electrochemiluminescence (Millipore, Billerica, MA, USA) following the manufacturer's instructions and quantified using ImageJ 1.8.0. 


\section{Quantitative real-time polymerase chain reaction ( $q R T$ - PCR)}

We extracted HCC tissue samples and total RNA from HCC cells using TRIzol (Invitrogen). miR-378a-5p expression was measured with the TaqMan MicroRNA Reverse Transcription Kit (TaKaRa, Otsu, Shiga, Japan) and miRNA-specific TaqMan microRNA assays (Applied Biosystems, San Diego, CA, USA). The qRT-PCR assays for miR-378a-5p detection were conducted on a SLAN96P RT-PCR instrument (Sansure Biotech, Changsha, Hunan, China). miR-378a-5p expression levels were expressed as fold differences relative to that of $R N U 6 B$ (RNA, U6 small nuclear 6, pseudogene, an internal control) using the comparative threshold cycle $\left(2^{-\Delta \Delta C t}\right)$ method. The RNU6B- and miR-378a-5p-specific forward primers were 5'-ACGCAAATTCGTGAAGCGTT-3' and 5'-CTGACTCCAGGTCCTGTGTA-3', respectively. The corresponding reverse primers were Uni-miR qRT-PCR primers (TaKaRa, Otsu, Shiga, Japan).

\section{Cell proliferation assay}

HCC cell proliferative ability was determined using Cell Counting Kit-8 (Dojindo, Kyoto, Japan). Cells $\left(3 \times 10^{5}\right.$ per well) were seeded in 6-well plates and maintained in an incubator. After transfection for $24 \mathrm{~h}, 5 \times 10^{3}$ cells per well were incubated in Dulbecco's modified eagle medium in 96well plates. The absorbance values of the experimental wells were read at $450 \mathrm{~nm}$ after $24,48,72$, and $96 \mathrm{~h}$ of incubation using a microplate reader.

\section{Colony formation assays}

Hep3B or SNU-449 cell lines were transfected for $48 \mathrm{~h}$. Next, we seeded and scattered the Hep3B or SNU-449 cells equally in 6-well tissue culture plates and cultured the cells in complete medium $(2 \mathrm{~mL})$. The culture medium was refreshed every 4 days with $1 \times$ phosphate buffer solution. At the end of the experiment, methanol was used to fix the surviving colonies, and crystal violet $(1.25 \%)$ was used to stain them. We counted colonies with at least 50 cells under a light microscope.

\section{Wound-bealing assays}

We seeded HCC cells $\left(3 \times 10^{5}\right.$ per well, 12 -well plates $)$ and incubated them for $24 \mathrm{~h}$ to form a monolayer of approximately $80 \%$ confluence. A scratch wound was gently made in each well using a pipette tip $(100 \mu \mathrm{L})$. Phasecontrast images of the same field were obtained at the 0 and $48 \mathrm{~h}$ under $100 \times$ magnification.

\section{Transwell assays}

We used a Transwell assay to measure the HCC cell migration and invasive ability using 24-well Transwell chambers. After $24 \mathrm{~h}$ of transfection, the upper chamber was filled with the cell suspensions, and the bottom chamber was filled with $10 \%$ FBS-containing medium. Next, we cultured the cells in a humidified incubator $\left(24 \mathrm{~h}, 5 \% \mathrm{CO}_{2}, 37^{\circ} \mathrm{C}\right)$. Subsequently, we fixed, stained by crystal violet $(1.25 \%)$, photographed, and counted the cells that had migrated or invaded and that had adhered to the surface on the bottom. Finally, the number of stained cells was determined under a microscope at $200 \times$.

\section{Dual-luciferase reporter gene analysis}

The has-miR-378a-5p target was identified by TargetScan online software (http://www.targetscan.org). VEGF oligonucleotides (positions 2088-2094) in which miR$378 \mathrm{a}-5 \mathrm{p}$ binding sites were present (WT) or deleted (MUT) were inserted in the pGL3-control vector to create recombinant plasmids according to the protocols. Luciferase activity was detected using Hep3B or SNU449 cells. After $48 \mathrm{~h}$ of incubation, the cells were lysed in cell culture luciferase lysis buffer, and the luciferase activity was analyzed using the Dual-Luciferase Reporter Assay System (Promega, USA). The relative activity of the luciferase was determined by the activity ratio of firefly luciferase to Renilla luciferase.

\section{Statistical analysis}

The data obtained from three separate experiments are expressed as the mean \pm standard error (SE). We analyzed the data with repeated-measures analysis of variance (ANOVA). Comparison between two groups was made using Student's $t$-tests. Correlations between two variables were analyzed with Pearson correlation analysis. The data were analyzed using GraphPad Prism 5 (GraphPad Software, San Diego, CA, USA) and SPSS 22.0 (SPSS Inc., Chicago, IL, USA). 
Table 1 Association between miR-378a-5p expression and clinicopathological characteristics

\begin{tabular}{|c|c|c|c|c|}
\hline Characteristic & No. of patients & $\bar{X} \pm S D$ & $\mathrm{t}$ & $\mathrm{P}$ \\
\hline Male & 20 & $0.38 \pm 0.13$ & 0.413 & 0.682 \\
\hline Female & 30 & $0.36 \pm 0.14$ & & \\
\hline \multicolumn{5}{|l|}{ Age, years } \\
\hline$\geq 50$ & 26 & $0.35 \pm 0.14$ & & \\
\hline \multicolumn{5}{|c|}{ Serum AFP, ng/mL } \\
\hline$\leq 20$ & 24 & $0.38 \pm 0.15$ & 0.800 & 0.427 \\
\hline$>20$ & 26 & $0.35 \pm 0.11$ & & \\
\hline Positive & 23 & $0.36 \pm 0.12$ & & \\
\hline \multicolumn{5}{|l|}{ Tumor size, mm } \\
\hline$\leq 10$ & 24 & $0.42 \pm 0.14$ & 3.249 & 0.002 \\
\hline$>10$ & 26 & $0.31 \pm 0.10$ & & \\
\hline \multicolumn{5}{|l|}{ TNM stage } \\
\hline $0 \& \mid \& \|$ & 27 & $0.42 \pm 0.13$ & 3.563 & 0.001 \\
\hline III \& IV & 23 & $0.30 \pm 0.10$ & & \\
\hline \multicolumn{5}{|c|}{ Distant metastasis } \\
\hline
\end{tabular}

\section{Results}

\section{Clinicopathological characteristics of HCC patients}

Expression of miR-378a-5p in HCC patient tissue was related to tumor size (in $\mathrm{mm} ; \mathrm{P}<0.05$ ), vascular invasion $(\mathrm{P}<0.001)$, distant metastasis $(\mathrm{P}<0.05)$, and $T N M$ stage $(\mathrm{P}<0.05)$. The relative miR-378a-5p expression was unassociated with age $(\mathrm{P}>0.05)$, sex $(\mathrm{P}>0.05)$, serum AFP $(\mathrm{P}>0.05)$, or serum HBsAg $(\mathrm{P}>0.05$; Table 1$)$.

\section{Low expression of miR-378a-5p and VEGF in HCC tissues}

The HCC tissues had significantly lower miR-378a-
$5 \mathrm{p}$ expression than the matched benign tissue samples $(\mathrm{t}=9.776, \mathrm{P}<0.001 ;$ Figure $1 A)$. The HCC tissue samples had significantly increased VEGF protein levels compared with the normal tissue samples $(\mathrm{t}=18.339, \mathrm{P}<0.001$; Figure $1 B)$. Interestingly, Pearson correlation analysis showed that miR-378a-5p expression correlated negatively with VEGF protein levels $\left(\mathrm{r}^{2}=0.6568, \mathrm{P}<0.001\right.$; Figure $\left.1 C\right)$.

\section{miR-378a-5p mimics inbibited proliferation in HCC cell lines}

The HCC cell lines in the miR-378a-5p mimics group had higher miR-378a-5p levels than that in the NC mimics 
A

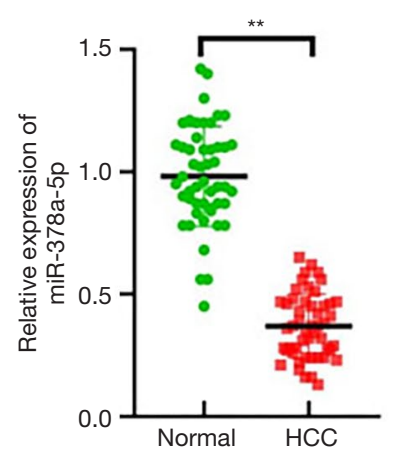

B
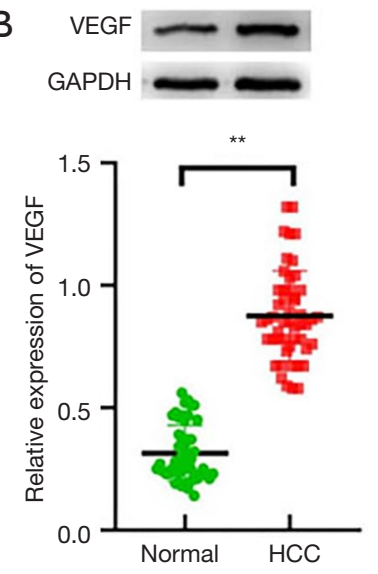

C

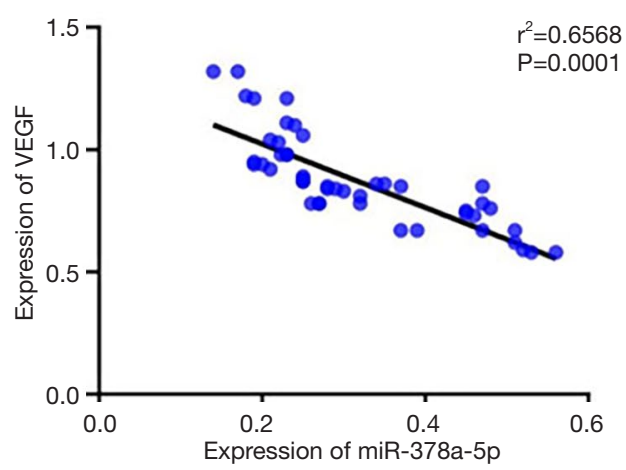

Figure 1 miR-378a-5p overexpression and VEGF downregulation in HCC tissues. (A) miR-378a-5p expression in HCC tissues was determined by RT-PCR; (B) VEGF expression in HCC tissues was detected via western blot assays; (C) correlation between miR-378a-5p levels and VEGF in HCC tissues. Data represent the mean $\pm \mathrm{SE}$. **, $\mathrm{P}<0.01$ was considered significant. VEGF, vascular endothelial growth factor; HCC, hepatocellular carcinoma.

A

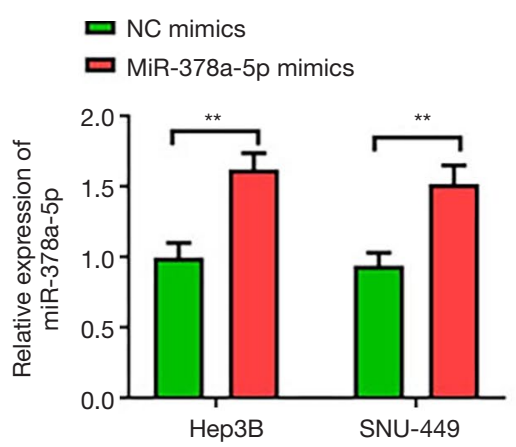

D
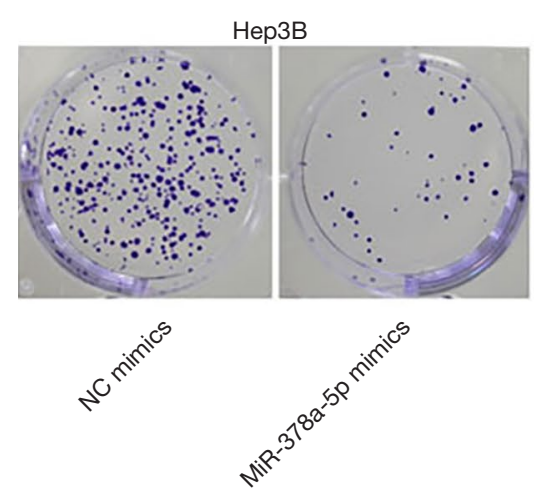

B
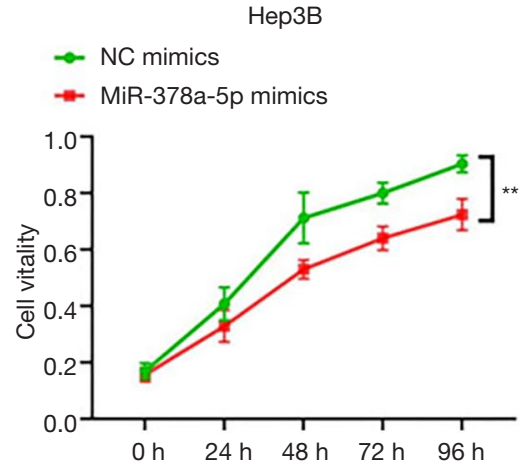

C

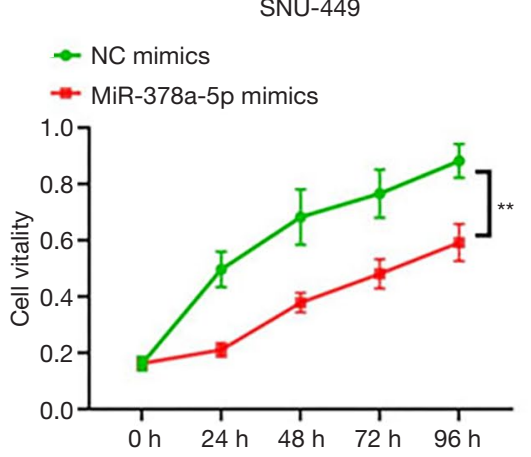

E
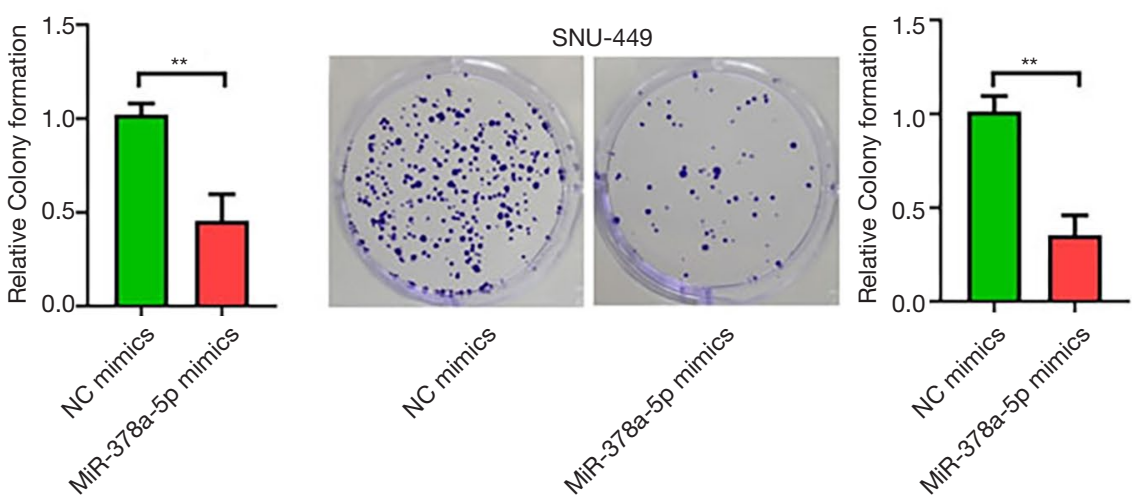

Figure 2 miR-378a-5p overexpression inhibited Hep3B and SNU-449 cell proliferation. (A) miR-378a-5p expression in Hep3B and SNU449 cells was determined via RT-PCR; (B,C) cell viability of Hep3B and SNU-449 cells was evaluated via CCK-8 assays; (D,E) clonogenic capacity of Hep3B and SNU-449 cells was assessed via cell colony formation assays. Representative images of the Hep3B and SNU-449 cells by photomicrographs $(200 \times)$. Data represent the mean $\pm \mathrm{SE} .{ }^{* *}, \mathrm{P}<0.01$ was considered significant. RT-PCR, real-time polymerase chain reaction. 

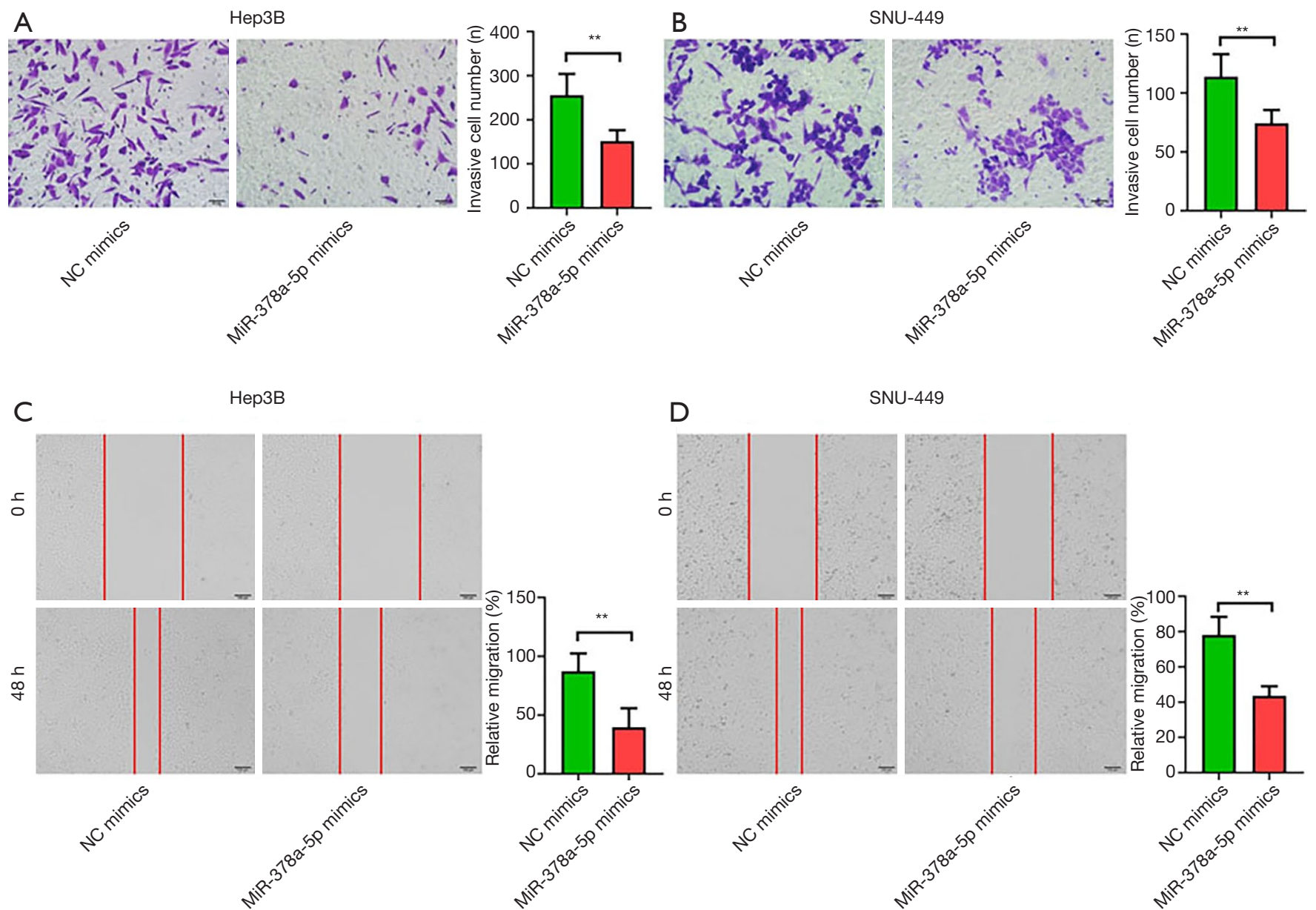

SNU-449

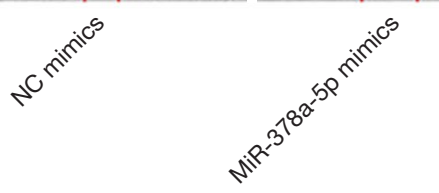

Figure 3 miR-378a-5p overexpression inhibited migratory and invasive capacity in Hep3B and SNU-449 cell lines. (A,B) Migratory capability of Hep3B and SNU-449 cells was evaluated by wound-healing assays; (C,D) invasion capability of Hep3B and SNU-449 cells was evaluated via Transwell invasion assays. Representative images of the Hep3B and SNU-449 cells by photomicrographs (400×). Data represent the mean $\pm \mathrm{SE}$. ${ }^{* *}, \mathrm{P}<0.01$ was considered significant.

(Hep3B: $\mathrm{t}=9.275, \mathrm{P}<0.001$; SNU-449: $\mathrm{t}=10.140, \mathrm{P}<0.001$; Figure $2 A$ ). The cell proliferation assay showed that the NC mimics had higher cell proliferative capacity than did the miR-378a-5p mimics in Hep3B $(\mathrm{F}=138.776, \mathrm{P}<0.001$; Figure $2 B)$ and SNU-449 ( $\mathrm{F}=156.889, \mathrm{P}<0.001$; Figure $2 C)$ cells. The colony formation assays showed that the miR$378 \mathrm{a}-5 \mathrm{p}$ mimics had reduced cell colony formation ability compared with the NC mimics (Hep3B: $\mathrm{t}=16.537, \mathrm{P}<0.001$; Figure 2D; SNU-449: $\mathrm{t}=21.874, \mathrm{P}<0.001$; Figure $2 E$ ).

\section{miR-378a-5p inbibited HCC cell migration and invasion}

In the Transwell cell migration assays, miR-378a-5p overexpression in Hep3B $(\mathrm{t}=6.086, \mathrm{P}<0.001$; Figure 3 A) and SNU-449 ( $\mathrm{t}=5.626, \mathrm{P}<0.001$; Figure $3 B)$ cell lines contributed to significantly decreased cell invasion compared with that in the NC mimics. In the woundhealing assays, downregulated miR-378a-5p promoted both Hep3B ( $\mathrm{t}=5.394, \mathrm{P}<0.001$; Figure $3 C)$ and SNU-449 $(\mathrm{t}=9.311, \mathrm{P}<0.001$; Figure $3 D)$ cell migration, while the number of invaded cells was markedly lower when miR$378 \mathrm{a}-5 \mathrm{p}$ mimics were transfected into the cells.

\section{miR-378a-5p reduced VEGF expression in HCC cell lines}

The miR-378a-5p mimics had significantly decreased VEGF protein expression compared with the NC mimics (Hep3B: $\mathrm{t}=11.490, \mathrm{P}<0.001$; Figure $4 A$ and $B$; SNU-449: 
A

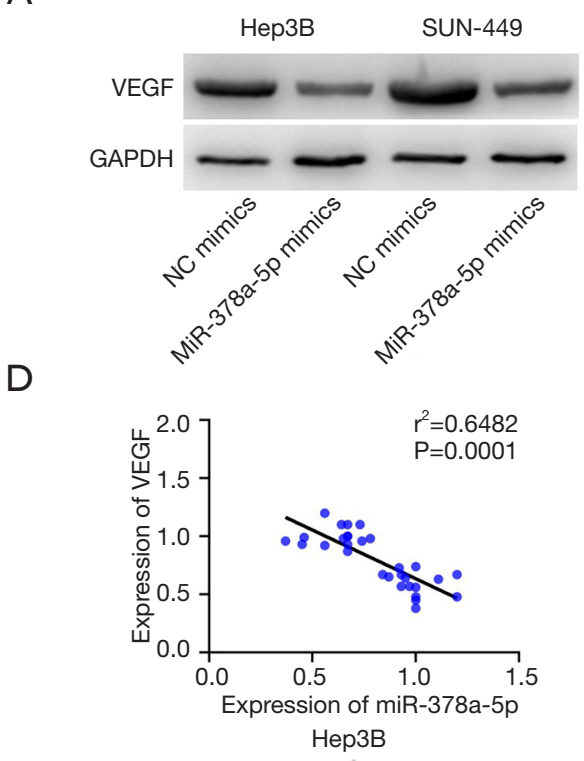

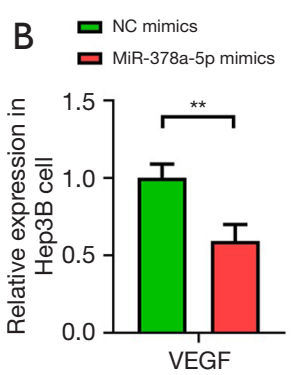

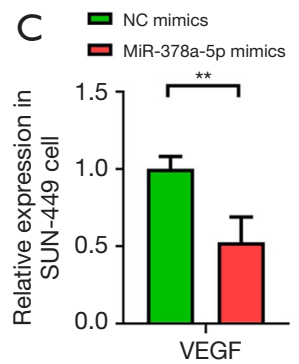

\section{E}

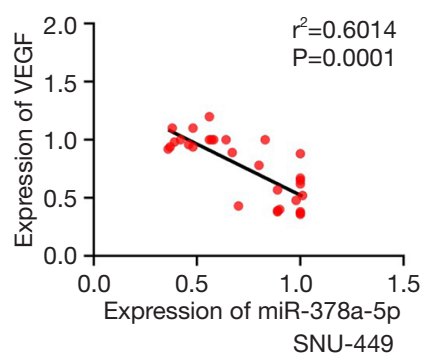

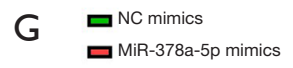

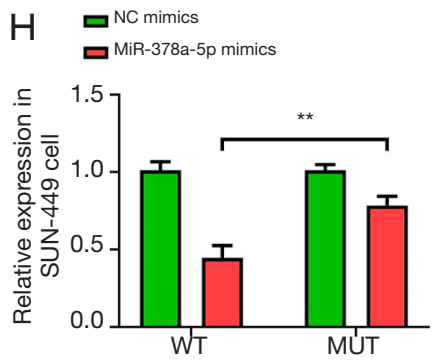

$\mathrm{F}$ VEGF 3, UTR 5' AUAGCUAGAUUUGUU'U⿴囗十)

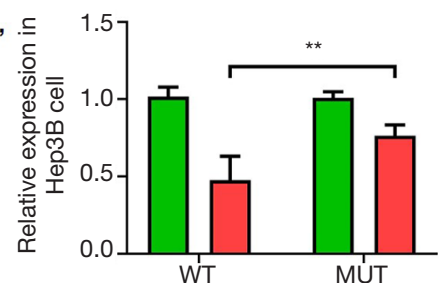

Figure 4 miR-378a-5p reduced VEGF expression in HCC cell lines. (A,B,C) VEGF expression in Hep3B and SNU-449 cells was examined via western blot assays; (D,E) correlation between miR-378a-5p levels and VEGF in Hep3B and SNU-449 cell lines; (F) wild-type miR378a-5p target sequences of VEGF mRNA 3'-UTR; (G,H) miR-378a-5p repressed the activity of pGL3-VEGF-WT but not pGL3-VEGFMUT in Hep3B and SNU-449 cells. Data represent the mean \pm SE. **, $\mathrm{P}<0.01$ was considered significant. VEGF, vascular endothelial growth factor; HCC, hepatocellular carcinoma.

$\mathrm{t}=10.134, \mathrm{P}<0.001$; Figure $4 A$ and $C)$. The miR-378a$5 \mathrm{p}$ expression and VEGF protein levels were negatively correlated (Hep3B: $\mathrm{r}^{2}=0.6482, \mathrm{P}<0.001$; Figure $4 D$; SNU449: $\mathrm{r}^{2}=0.6014, \mathrm{P}<0.001$; Figure $\left.4 E\right)$. TargetScan analysis showed that miR-378a-5p targeted VEGF (Figure 4F), and luciferase assays revealed that miR-378a-5p repressed the activity of pGL3-VEGF-WT but not of pGL3-VEGFMUT in Hep3B ( $\mathrm{t}=10.134, \mathrm{P}<0.001$; Figure $4 G)$ and SNU449 ( $\mathrm{t}=10.134, \mathrm{P}<0.001$; Figure $4 H)$ cells.

\section{Discussion}

Here, we report that miR-378a-5p expression was commonly downregulated in HCC tissues and correlated with HCC progression. Upregulation of miR-378a-5p expression reduced Hep3B and SNU-449 cell viability, proliferation, invasion, and migration. We also found that miR-378a-5p targeted and suppressed VEGF signaling, and the two were negatively correlated. The present results show that miR-378a-5p has a tumor-suppressive role in HCC progression by targeting VEGF signaling, which has previously been rarely reported.

Evidence has shown that miR-378a-5p is abnormally regulated in renal cell carcinoma (17) and stage II colon cancer (15). Here, miR-378a-5p expression was low in the HCC tissues and was related to TNM stage, distant 
metastasis, and vascular invasion. Our findings show that miR-378a-5p acts as an anti-tumor factor and might play a key role in HCC prognosis, metastasis, and progression.

Studies have shown the crucial roles of miR-378a-5p in impeding cell viability, invasion, proliferation, and migration $(17,22)$. Our results showed that transfection of miR-378a$5 \mathrm{p}$ mimics markedly decreased cell vitality and colony formation. Furthermore, miR-378a-5p expression led to reduced $\mathrm{HCC}$ cell invasion and migration, indicating that miR-378a-5p negatively regulated HCC cell progression. miR-378a-5p's antitumor effect in this study is consistent with that in Pan et al.'s study, where, in renal cell carcinoma, miR-378a-5p was described as playing a tumor-suppressive role and was associated with a good prognosis (17). Another study showed that miR-378a-5p overexpression promoted vascular smooth muscle cell migration and proliferation (23). Excess miR-378a-5p has also been correlated with breast cancer tumorigenesis in vivo (18). Thus, whether the antitumor effects induced by miR-378a-5p are bidirectional and concentration-dependent require further study.

Cheng et al. found that the VEGF signaling pathway promoted HCC cell invasion, migration, and angiogenesis in vitro (24). Here, HCC tissues and cell lines had significantly increased VEGF protein levels, and VEGF expression in the Hep3B and SNU-449 cells was decreased by miR-378a-5p overexpression. Expression of miR-378a$5 p$ was negatively associated with Hep3B and SNU-449 HCC cells. Moreover, we confirmed VEGF as the target of miR-378a-5p in HCC cells. These data demonstrated that miR-378a-5p produced antitumor effects by inhibiting VEGF. Research shows that the main mechanism of VEGF in tumor invasive and metastatic progression is that VEGF directly stimulates vascular endothelial cell differentiation, proliferation and migration and degrades vascular basement membranes, which promotes shedding of cancer cells into blood vessels, then transfers them to the adjacent fibrin $(25,26)$. VEGF promotes formation of new lymphatic vessels around and inside tumors as well as original lymphangitic hyperplasia and increased vessel diameter. VEGF also facilitates tumor cells to lymphatic metastasis (27). However, cyclin-dependent kinase 6 is also a target signaling pathway of the tumor suppressor functions of miR-378 (19), which will be explored in future research.

\section{Conclusions}

In summary, miR-378a-5p inhibited tumors in HCC and in two HCC cell lines, and low expression of miR-378a-
$5 \mathrm{p}$ is a potential poor prognostic marker in patients with HCC. miR-378a-5p affects the migration, invasion, and proliferation of HCC cells by targeting the VEGF signaling pathway. With biological and clinical implications in HCC, miR-378a-5p has potential value in HCC therapy and may be a good prognostic and confirmatory diagnostic marker in HCC tumorigenesis.

\section{Acknowledgments}

Funding: Scientific Research Project of Sichuan Provincial Health and Family Planning Commission (No. 16PJ448).

\section{Footnote}

Conflicts of Interest: All authors have completed the ICMJE uniform disclosure form (available at http://dx.doi. org/10.21037/tcr.2020.01.46). The authors have no conflicts of interest to declare.

Ethical Statement: The authors are accountable for all aspects of the work in ensuring that questions related to the accuracy or integrity of any part of the work are appropriately investigated and resolved. The study was conducted in accordance with the Declaration of Helsinki (as revised in 2013). The Sichuan Academy of Medical Sciences and Sichuan Provincial People's Hospital Ethics Committee approved all study protocols and informed consent was taken from all individual participants.

Open Access Statement: This is an Open Access article distributed in accordance with the Creative Commons Attribution-NonCommercial-NoDerivs 4.0 International License (CC BY-NC-ND 4.0), which permits the noncommercial replication and distribution of the article with the strict proviso that no changes or edits are made and the original work is properly cited (including links to both the formal publication through the relevant DOI and the license). See: https://creativecommons.org/licenses/by-nc-nd/4.0/.

\section{References}

1. El-Serag HB, Zhu AX, Johnson MS. The treatment path in hepatocellular carcinoma. Clin Adv Hematol Oncol 2017;15 Suppl 9:1-20.

2. Lou W, Chen J, Ding B, et al. Identification of invasionmetastasis-associated microRNAs in hepatocellular carcinoma based on bioinformatic analysis and 
experimental validation. J Transl Med 2018;16:266.

3. Chen W, Yan X, Yang A, et al. miRNA-150-5p promotes hepatic stellate cell proliferation and sensitizes hepatocyte apoptosis during liver fibrosis. Epigenomics 2020;12:53-67.

4. Han D, Li J, Wang H, et al. Circular RNA circMTO1 acts as the sponge of microRNA-9 to suppress hepatocellular carcinoma progression. Hepatology 2017;66:1151-64.

5. Erridge S, Pucher PH, Markar SR, et al. Meta-analysis of determinants of survival following treatment of recurrent hepatocellular carcinoma. Br J Surg 2017;104:1433-42.

6. Shah C, Mramba LK, Bishnoi R, et al. Survival differences among patients with hepatocellular carcinoma based on the stage of disease and therapy received: pre and post sorafenib era. J Gastrointest Oncol 2017;8:789-98.

7. Liu C, Zhong X, Li J, et al. Circular RNA circVAPA Promotes Cell Proliferation in Hepatocellular Carcinoma. Hum Gene Ther Clin Dev 2019;30:152-9.

8. Zhang M, Song Y, Yu L. LncRNA PTCSC3 suppressed cervical carcinoma cell invasion and proliferation via regulating miR-574-5p. Am J Transl Res 2019;11:7186-94.

9. Fang F, Chang RM, Yu L, et al. MicroRNA-188-5p suppresses tumor cell proliferation and metastasis by directly targeting FGF5 in hepatocellular carcinoma. J Hepatol 2015;63:874-85.

10. Tan G, Wu L, Tan J, et al. MiR-1180 promotes apoptotic resistance to human hepatocellular carcinoma via activation of NF-kappaB signaling pathway. Sci Rep 2016;6:22328.

11. Zhang H, Liu H, Bi H. MicroRNA-345 inhibits hepatocellular carcinoma metastasis by inhibiting YAP1. Oncol Rep 2017;38:843-9.

12. Chang RM, Xiao S, Lei X, et al. miRNA-487a Promotes Proliferation and Metastasis in Hepatocellular Carcinoma. Clin Cancer Res 2017;23:2593-604.

13. Li B, Liu D, Yang P, et al. miR-613 inhibits liver cancer stem cell expansion by regulating SOX9 pathway. Gene 2019;707:78-85.

14. Chen CF, Hua K, Woung LC, et al. Expression Profiling of Exosomal miRNAs Derived from the Aqueous Humor of Myopia Patients. Tohoku J Exp Med 2019;249:213-21.

15. Gungormez C, Gumushan Aktas H, Dilsiz N, et al. Novel miRNAs as potential biomarkers in stage II colon cancer: microarray analysis. Mol Biol Rep 2019;46:4175-83.

16. Kooistra SM, Norgaard LC, Lees MJ, et al. A screen identifies the oncogenic micro-RNA miR-378a-5p as a negative regulator of oncogene-induced senescence. PLoS One 2014;9:e91034.

17. Pan X, Zhao L, Quan J, et al. MiR-378a-5p acts as a tumor suppressor in renal cell carcinoma and is associated with the good prognosis of patients. Am J Transl Res 2019;11:2207-18.

18. Winsel S, Maki-Jouppila J, Tambe M, et al. Excess of miRNA-378a-5p perturbs mitotic fidelity and correlates with breast cancer tumourigenesis in vivo. Br J Cancer 2014;111:2142-51.

19. Deng H, Guo Y, Song H, et al. MicroRNA-195 and microRNA-378 mediate tumor growth suppression by epigenetical regulation in gastric cancer. Gene 2013;518:351-9.

20. Youssef AA, Issa HA, Omar MZ, et al. Serum human endothelial cell-specific molecule-1 (endocan) and vascular endothelial growth factor in cirrhotic $\mathrm{HCV}$ patients with hepatocellular carcinoma as predictors of mortality. Clin Exp Gastroenterol 2018;11:431-8.

21. Lorente L. New prognostic biomarkers of mortality in patients undergoing liver transplantation for hepatocellular carcinoma. World J Gastroenterol 2018;24:4230-42.

22. Zanutto S, Pizzamiglio S, Ghilotti M, et al. Circulating miR378 in plasma: a reliable, haemolysis-independent biomarker for colorectal cancer. Br J Cancer 2014;110:1001-7.

23. Liu S, Yang Y, Jiang S, et al. MiR-378a-5p Regulates Proliferation and Migration in Vascular Smooth Muscle Cell by Targeting CDK1. Front Genet 2019;10:22.

24. Cheng W, Cheng Z, Xing D, et al. Asparagus Polysaccharide Suppresses the Migration, Invasion, and Angiogenesis of Hepatocellular Carcinoma Cells Partly by Targeting the HIF-1alpha/VEGF Signalling Pathway In Vitro. Evid Based Complement Alternat Med 2019;2019:3769879.

25. Dai W, Wang Y, Yang T, et al. Downregulation of exosomal CLEC3B in hepatocellular carcinoma promotes metastasis and angiogenesis via AMPK and VEGF signals. Cell Commun Signal 2019;17:113.

26. Oh CR, Kong SY, Im HS, et al. Genome-wide copy number alteration and VEGFA amplification of circulating cell-free DNA as a biomarker in advanced hepatocellular carcinoma patients treated with Sorafenib. BMC Cancer 2019;19:292.

27. Mao CS, Yin H, Ning HB, et al. Levels of HBx, VEGF, and CEACAM1 in HBV-related hepatocellular carcinoma and their correlation with cancer prognosis. Eur Rev Med Pharmacol Sci 2017;21:3827-33.

Cite this article as: Zou H, Yang L. miR-378a-5p improved the prognosis and suppressed the progression of hepatocellular carcinoma by targeting the VEGF pathway. Transl Cancer Res 2020;9(3):1558-1566. doi: 10.21037/tcr.2020.01.46 